\title{
Evaluation of the Thermal Stability of Poly (O-phenylenediamine) (PoPD) by Thermogravimetric Analysis (TGA)
}

\author{
Nkamuo Chinwe Juliana ${ }^{1}$, Nwokoye Anthony Osita Chibuike ${ }^{2}$, Ekpunobi Azubuike Josiah ${ }^{2}$ \\ ${ }^{1}$ Department of Science Laboratory Technology, Federal Polytechnic, Oko, Nigeria \\ ${ }^{2}$ Department of Physics and Industrial Physics, Nnamdi Azikiwe University, Awka, Nigeria
}

Email address:

chybenas1@gmail.com (N. C. Juliana)

\section{To cite this article:}

Nkamuo Chinwe Juliana, Nwokoye Anthony Osita Chibuike, Ekpunobi Azubuike Josiah. Evaluation of the Thermal Stability of Poly (Ophenylenediamine) (PoPD) by Thermogravimetric Analysis (TGA). American Journal of Nanosciences. Vol. 5, No. 2, 2019 , pp. 18-22. doi: 10.11648/j.ajn.20190502.11

Received: September 18, 2019; Accepted: October 5, 2019; Published: October 23, 2019

\begin{abstract}
The poly (o-phenylenediamine) (PoPD) was synthesized from the monomer o-phenylenediamine in hydrochloric acid $(\mathrm{HCl})$ using potassium dichromate as an oxidant by chemical oxidation method. The prepared PoPD sample was characterized by thermogravimetric analyzer (TGA) and scanning electron microscopy (SEM). The thermogravimetric analysis (TGA) results showed that a weight loss occurred. The weight loss as a result of the thermal energy applied to the polymer sample is $9.649 \mathrm{mg}$ which is $85.0 \%$ of the original polymer sample. The point of the greatest rate of change on the weight loss curve (point of inflection) is found to be $275^{\circ} \mathrm{C}$ and is the peak temperature of the degradation of the PoPD. SEM analysis showed that the PoPD sample has particle sizes ranging from $200 \mu \mathrm{m}-50 \mu \mathrm{m}$ at 360 magnification, $500 \mu \mathrm{m}-50 \mu \mathrm{m}$ at 1000 magnification, $200 \mu \mathrm{m}-50 \mu \mathrm{m}$ at 1550 magnification and $500 \mu \mathrm{m}-150 \mu \mathrm{m}$ at 2000 magnification which revealed more unevenly dispersed particles of the poly (o-phenylenediamine) polymer at different magnifications. Therefore poly (ophenylenediamine) has different particle sizes and is also thermally stable at a higher temperature of $150^{\circ} \mathrm{C}$.
\end{abstract}

Keywords: Thermal Stability, PoPD, TGA, SEM

\section{Introduction}

The discovery of conductive polymers has led to new technology. When interesting properties of material are observed in the laboratory, efforts are made to understand their mechanisms, which lead to the fine control of the fabrication process of this new and potentially important material [1]. Conducting polymers have been a popular area of investigation because of their potential application areas. Polymerization of a conducting polymer may be performed with chemical or electrochemical [2] methods. Different chemical oxidizing agents such as potassium dichromate [3, 4], potassium iodate, [5], hydrogen peroxide [6], Ferric chloride or ammonium persulphate [7] can be used. Polymers have been extensively studied as new materials for electronic and optoelectronic applications. The demands made on electronic components are constantly increasing. Aniline is an important member of intrinsically conducting polymer. Phenylenediamine belong to aniline derivatives and PoPD shows different properties when compared to aniline [8]. Among the conducting polymers, PoPD, a highly aromatic polymer containing 2,3-diaminophenazine or quinoxaline repeating unit has received significant attention because it can be utilized in many fields [9]. The derivatives of polyaniline are found applications in different fields like removal of heavy metals from industrial effluents, anticorrosive agents [10], electromagnetic shielding and in optics [11-15]. Thermogravimetric analysis (TGA) of PoPD nanofibers possess good thermal stability [9]. A TGA can be used for material characterization through analysis of characteristic decomposition patterns. It is an especially useful technique for the study of polymeric materials. Thus a TGA is a method of thermal analysis in which the mass of a sample is measured over time as the temperature changes. It 
can be used to evaluate the thermal stability of a material. TGA also gives the upper use temperature of a material beyond which the material will begin to degrade. Most polymers melt or degrade before $200^{\circ} \mathrm{C}$. However, there is a class of thermally stable polymers that are able to withstand temperature of at least $300^{\circ} \mathrm{C}$ in air and $500^{\circ} \mathrm{Cin}$ inert gases without structural changes or strength loss, which can be analyzed by TGA $[16,17]$. In this work, TGA was used to analyze the thermal stability of PoPD using chemical oxidation technique. TGA curve was plotted to determine the inflection point useful for in-depth interpretations as well as differential thermal analysis (DTA). The scanning electron microscopy (SEM) which is the most versatile one available is used for the examination analysis of the microstructure morphology of the PoPD. ImageJ for microscopic image analysis is used to determine the average particle size from micrograph images [18].

\section{Experimental}

\subsection{Materials}

The (o-phenylenediamine) (oPD) used in this work was procured from Quallkems. The potassium dichromate $\left(\mathrm{K}_{2} \mathrm{Cr}_{2} \mathrm{O}_{7}\right)$ was procured from Kermel. The concentrated Hydrochloric $(\mathrm{HCl})$ acid was procured from Sigma Aldrich, Oceanic chemicals Nig. Ltd.

\subsection{Synthesis of PoPD}

$1.622 \mathrm{~g}$ of (o-phenylenediamine) (oPD) was added to $50 \mathrm{ml}$ of $0.1 \mathrm{M}$ of $\mathrm{HCl}$. The solution was heated and stirred for about 5 minutes. The temperature of the solution was brought down to $20^{\circ} \mathrm{C}$. Then $50 \mathrm{ml}$ of potassium dichromate $\left(\mathrm{K}_{2} \mathrm{Cr}_{2} \mathrm{O}_{7}\right)$ was used as the oxidizing agent and was prepared by dissolving $4.413 \mathrm{~g}$ of $\mathrm{K}_{2} \mathrm{Cr}_{2} \mathrm{O}_{7}$ in $50 \mathrm{ml}$ of $0.1 \mathrm{M}$ of $\mathrm{HCl}$. The dissolved $\mathrm{K}_{2} \mathrm{Cr}_{2} \mathrm{O}_{7}$ was set to drop bit by bit (dropwise) with the help of a burette with a flow rate of $1.43 \mathrm{ml} / \mathrm{mins}$. The solution was left for $24 \mathrm{hrs}$. Then, the poly (ophenylenediamine) was collected after filteration and repeated washing with distilled water and allowed to dry at a temperature of $50^{\circ} \mathrm{C}$.

\subsection{Sample Characterization}

The prepared PoPD sample was characterized with TGA and SEM.

\section{Results}

\subsection{Thermogravimetric Analyzer (TGA)}

Thermogravimetric analyzer (TGA) measures the amount of weight change of a material, either as a function of increasing temperature or isothermally as a function of time, in an atmosphere of Nitrogen, Helium, air, other gas or in vacuum. Figure 1 shows the thermogram of the poly (ophenylenediamine) with sample weight of $11.352 \mathrm{mg}$.

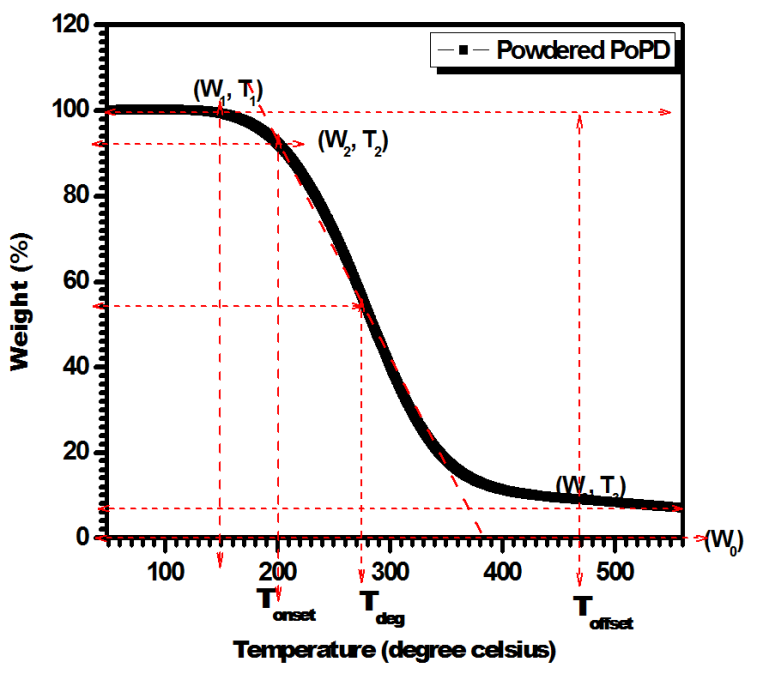

Figure 1. Thermogram (TGA) of PoPD sample.

Figure 2 shows the time derivatives of the weight loss against temperature.

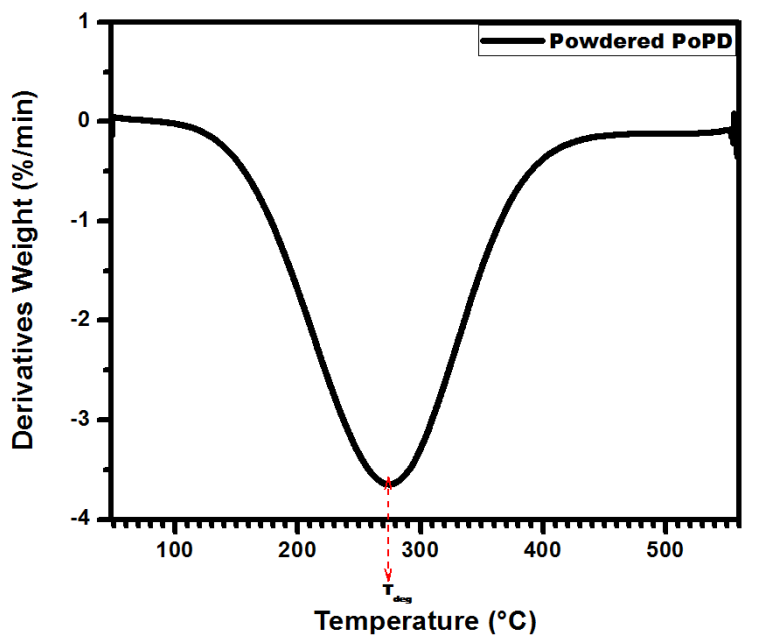

Figure 2. Derivative Thermogram (DTA) of PoPD sample.

The combination of TGA and DTA of sample is shown in figure 3 .

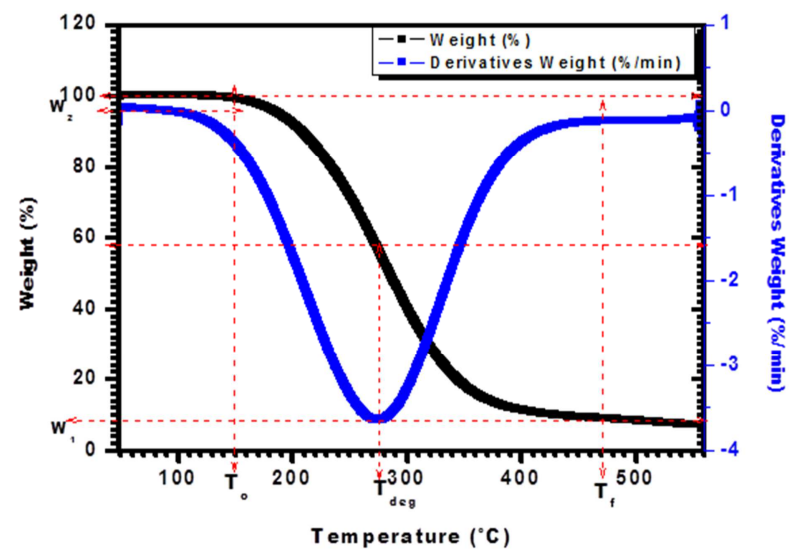

Figure 3. Thermogram (TGA) and Derivative Thermogram (DTA) of PoPD sample. 


\subsection{Scanning Electron Microscope (SEM) Images Analysis}

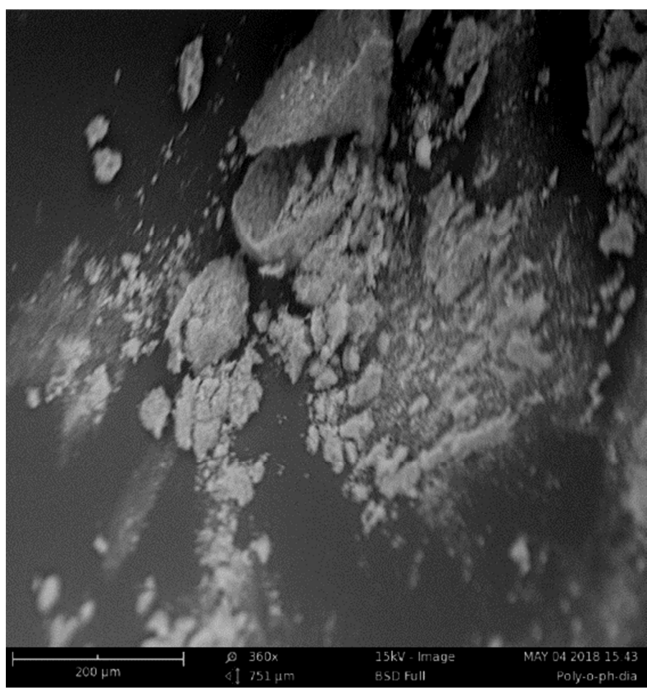

Figure 4. SEM Image of PoPD at 360 magnification

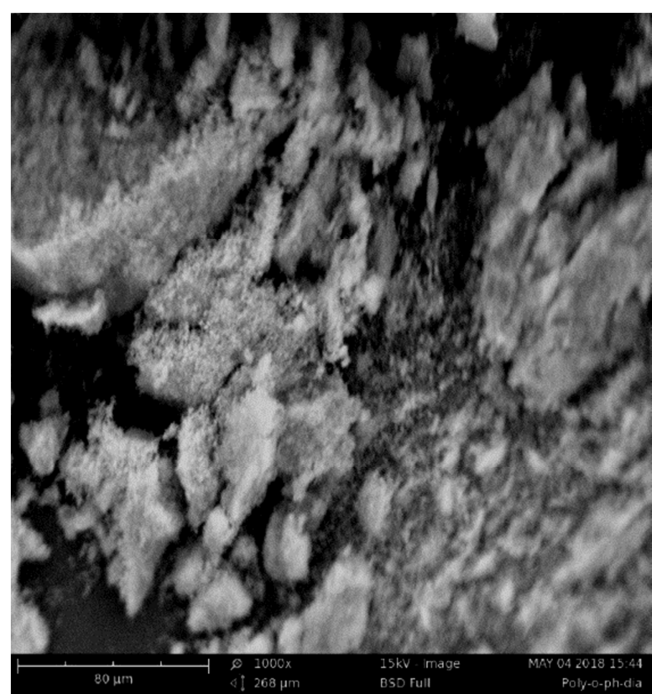

Figure 5. SEM Image of PoPD at 1000 magnification.

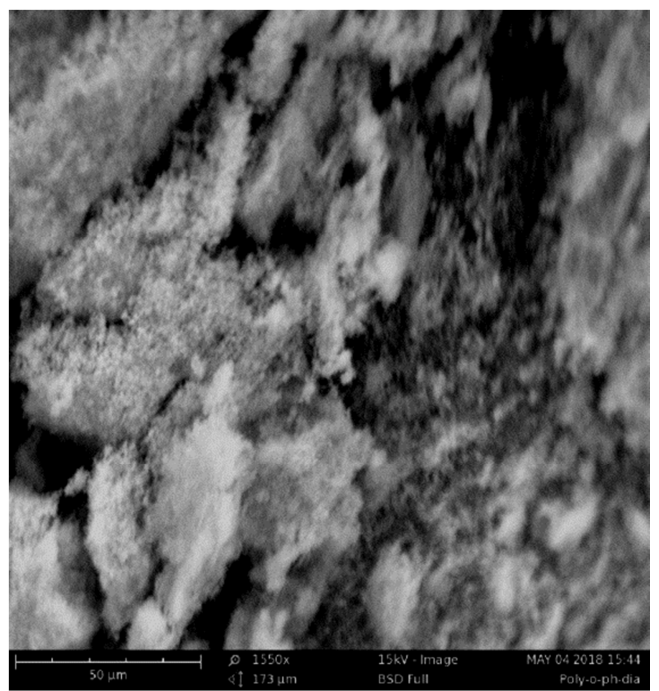

Figure 6. SEM Image of PoPD at 1550 magnification.

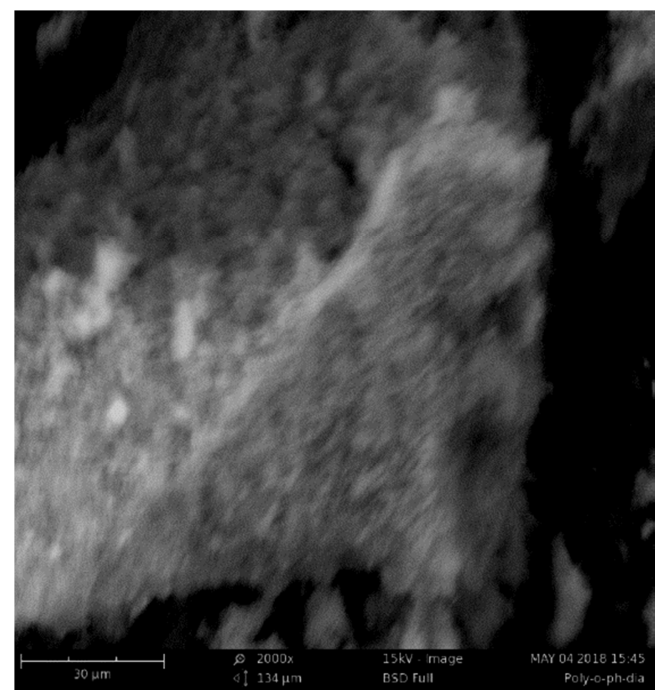

Figure 7. SEM Image of PoPD at 2000 magnification.

\section{Discussion}

\subsection{Thermogravimetric Analysis (TGA)}

The descending TGA thermal curve shown in figure 1 indicates that weight loss occurred due to application of heat to the powder polymer sample. The temperature of the heat applied ranged from $45.00^{\circ} \mathrm{C}$ to $950.00^{\circ} \mathrm{C}$ at $10.00^{\circ} \mathrm{C} / \mathrm{min}$ with Nitrogen as atmospheric condition. Beyond $572^{\circ} \mathrm{C}$ the sample shows no further degradation. The thermogram in figure 1 gives the various stages that lead to the thermal degradation of the synthesized polymer. The thermogram provide quantitative information such as loss of water (\%), loss of solvents (\%), pyrolysis (thermal decomposition), oxidation, and weight of ash or residual (\%). The summary of the thermal degradation process is shown in table 1 .

From table 1, the weight percentage of moisture content (water and other solvent) removed from the actual weight of the synthesized poly (o-phenylenediamine) within the onset temperature $\left(T_{\text {onset }}\right)$ of $150^{\circ} \mathrm{C}$ and offset temperature of $200^{\circ} \mathrm{C}$ is given in the first stage. $8.0 \%$ which is equivalent to $0.908 \mathrm{mg}$ of the actual sample used for the TGA analysis was lost. The second stage involves thermal decomposition (pyrolysis) of the sample with an onset temperature of $200^{\circ} \mathrm{C}$ and offset temperature of $470^{\circ} \mathrm{C}$. The percentage weight loss in this stage is $85.0 \%$ which is equal to $9.649 \mathrm{mg}$ of the original sample. The third stage which contain residual in form of charcoals has an onset temperature of $470^{\circ} \mathrm{C}$ and offset temperature of $572^{\circ} \mathrm{C}$. Percentage weight of the residual remaining is $7.0 \%$ which represents $0.795 \mathrm{mg}$. Therefore, the weight loss as a result of the thermal energy applied to the polymer sample is $9.649 \mathrm{mg}$ which represents about $85 \%$ of the original polymer sample. The temperature of the onset of thermal degradation was observed at $200^{\circ} \mathrm{C}$ while the offset temperature of thermal degradation is found to be $470^{\circ} \mathrm{C}$.

At any given temperature in figure 2, the rate of weight loss is a function of the amount of original material remaining, the nature and relative amount of degradation product (residue) present. The peak temperature of the derivative indicates the point of greatest rate of change on the 
weight loss curve shown in figure 4.13. This is known as point of inflection and is the most sensitive point at the temperature axis. This corresponds to the point at which the curve is changing direction at the greatest rate which can also be regarded as the peak degradation temperature. The peak temperature of degradation of the PoPDA is found to be $275^{\circ} \mathrm{C}$. Figure 4.15 shows both the thermogram and the derivative of the thermogram. The derivative of weight loss is measured in percentage of weight loss per minute.

Table 1. Analysis of the stages on weight loss in the thermogram of PoPD powder.

\begin{tabular}{llll}
\hline Stages & Change in weight (\%) & Loss of mass $(\mathbf{m g})$ & Temperature change $=\boldsymbol{T}_{\text {offset }}-\boldsymbol{T}_{\text {onset }}\left({ }^{\circ} \mathrm{C}\right)$ \\
\hline $1^{\text {st }}$ (loss of water) & $W_{1}-W_{2}=100-92=8.0$ & $\frac{8.0}{100} \times 11.352=0.908$ & $200-150=50$ \\
$\begin{array}{l}2^{\text {nd }} \text { (Pyrolysis or Thermal } \\
\text { decomposition) }\end{array}$ & $W_{2}-W_{3}=92-7=85.0$ & $\frac{85}{100} \times 11.352=9.649$ & $470.0-200.0=270$ \\
$3^{\text {rd }}$ (Residual) & $W_{3}-W_{0}=7-0=7$ & $\frac{7}{100} \times 11.352=0.795$ & $572-470=102$ \\
\hline
\end{tabular}

\subsection{Scanning Electron Microscpoy (SEM) Analysis}

For poly (o-phenylenediamine) at 360 magnification (Figure 4), SEM analysis showed that the sample had particle sizes ranging from $200 \mu \mathrm{m}-50 \mu \mathrm{m}$. Uneven masses littered the surface of the sample were observed at a lower magnification.

For poly (o-phenylenediamine) at 1000 magnification (Figure 5), SEM analysis showed that the sample had particle sizes ranging from $500 \mu \mathrm{m}-50 \mu \mathrm{m}$. Uneven masses littered the surface of the sample were observed at a lower magnification.

For poly (o-phenylenediamine) at 1550 magnification (Figure 6), SEM analysis showed that the sample had particle sizes ranging from $200 \mu \mathrm{m}-50 \mu \mathrm{m}$. Uneven masses littered the surface of the sample were observed at a higher magnification.

For poly (o-phenylenediamine) at 2000 magnification (Figure 7), SEM analysis showed that the sample had particle sizes ranging from $500 \mu \mathrm{m}-150 \mu \mathrm{m}$. Uneven masses littered the surface with a very large mass of the sample were observed at a higher magnification.

Therefore the poly (o-phenylenediamine) sample has different particle sizes at different magnifications.

\section{Conclusion}

The synthesis of poly o-phenylenediamine in $\mathrm{HCl}$ medium with potassium dichromate as an oxidizing agent using chemical method was successfully achieved. Thermogravimetric analysis (TGA) was used to determine the thermal properties (stability) of the prepared PoPD. The thermogravimetric analysis (TGA) results showed that a weight loss occurred. It shows a weight loss of moisture content of $8.0 \%(0.908 \mathrm{mg})$ of actual sample used and a weight loss (thermal decomposition or pyrolysis) of $85.0 \%$ $(9.649 \mathrm{mg})$ of the original sample with the percentage weight of the remaining residual of $7.0 \%(0.795 \mathrm{mg})$. The weight loss as a result of the thermal energy applied to the polymer sample is $9.649 \mathrm{mg}$ which is $85.0 \%$ of the original polymer sample. The polymer sample has a thermal stability of $150^{\circ} \mathrm{C}$ and the point of the greatest rate of change on the weight loss curve (point of inflection) is found to be $275^{\circ} \mathrm{C}$ which is the peak temperature of the degradation of the PoPD. Also the
PoPD has different particle sizes ranging from $500 \mu \mathrm{m}-50 \mu \mathrm{m}$ at different magnifications from SEM images.

\section{Recommendations}

Having successfully polymerized PoPD using potassium dichromate by chemical oxidation method the following recommendations are made for further studies;

i. The use of other oxidizing agents other than potassium dichromate for the synthesis of PoPD.

ii. The use of electropolymerization method in different acid medium with different substrates.

\section{Contributions}

i. Determination of the thermal stability of the PoPD.

ii. Determination of the point of inflection of the PoPD.

\section{Conflict of Interest}

The authors declare that there is no conflict of interests regarding the publication of the paper.

\section{References}

[1] Aga, R. S. and Mu, R. R. (2010). Doping of polymers with $\mathrm{ZnO}$ nanostructures foroptoelectronic and sensor applications. In L. Nicoleta (Ed.), Nanowires Science and Technology (pp. 205-222). Romania: National Institute of Research and Development for Technical Physics.

[2] Omar, M. and Mariam, J. (2017). Copolymerization of poly ophenylenediamine-co-o/p Toluidinevia the chemical oxidative technique. Synthesis and characterization. Materialsand Technology, 51 (2), 283-288.

[3] Sayyah, S. M., Khahiel, A. B., Ahmed, A. A. and Mohamed, S. M. (2014). Chemicalpolymerization kinetics of poly ophenylenediamine and characterization of the obtainedpolymer in aqueous hydrochloric acid solution using $\mathrm{K} 2 \mathrm{Cr} 2 \mathrm{O} 7$ as oxidizing agent. International Journal of Polymer Science, 2014, 1-16.

[4] Melad, O. (2016). Chemical oxidative synthesis of characterization of poly o- phenylenediaminedoped with different acids. European Journal of Chemistry. 7 (4), 463467. 
[5] Hirase, R., Shikata, T. and Shirai, M. (2004). Selective formation of polyanline on wool bychemical polymerization, using potassium iodate. Synth. Met., 146, 73-77.

[6] Gopalakrishnan, K., Elango, M. and Thamilsevan, M. (2012). Optical studies on nano-structuredconducting polyaniline prepared by oxidation method. Archives of Phys. Research 3, 315-319.

[7] Molapo, K., Nlangili, P. M. and Ajayi, R. F. (2012). Electronics of conjugated polymers: Polyaniline. Int. Journal of Electrochem. Sci., 7, 11859-11875.

[8] Salma, B. L., Anwar-ul-Haq, A. S. and Rudolf, H. (2011). Spectroelectrochemistry ofpoly (o-phenylenediamine: polyaniline-like segments in the polymer structure. EletrochimActa, 56, 3353-3358.

[9] Muthirulan, P., Kannan, N. and Meenakshisundaram M., (2013). Synthesis and Corrosion Protection properties of Poly o- phenylenediamine nanofibers. Journal of advanced research, 4, 385-392.

[10] Suresh, K. V., Venkatraman, B. R., Shobana, V. and Subramania, A. (2012). Polythiophene Naphthosulphonic acid: New and effective corrosion inhibitor for carbon steel in acidsolution. Research Journal of Chemical Science, 2 (10), 87-94.

[11] Xiang, C., Xie, Q., Hu, J. and Yao, S. (2006). Studies on electrochemical copolymerization of aniline with ophenylenediamine and degradation of the resultant copolymers viaelectrochemical quartz crystal microbalance and scanning electrochemical microscope. Synth. Met., 156, 444-453.
[12] Kong, Y., Li, W., Wang, Z., Yao, C. and Tao, Y. (2013). Electrosorption behavior of copperions with poly $\mathrm{m}$ phenylenediamine paper electrode. Electrochem Comm., 26, 59-62.

[13] Saxens, D., Dwivedi, V. and Mishra, P. K. (2013). Dielectric study of polyaniline in frequencyrange $100 \mathrm{~Hz}$ to $500 \mathrm{~Hz}$ at Temperature $200 \mathrm{oC}$ and $300 \mathrm{oC}$. Research Journal of Chemical Science, 3 (2), 16-19.

[14] Shanthi, T. and Rajendran, S. (2013). Influence of polyvinyl pyrolidone on corrosionresistance of mild steel simulated concrete pore solution prepared in well water. Research Journal of Chemical Science, 3 (9), 39-44.

[15] Archana, S. and Jaya, S. R. (2014). Synthesis and characterization of poly (p-phenylenediamine) in the presence of sodium dodecylsulphate. Research Journal of Chemical Science, 4 (2), 60-67.

[16] Liu, X. and Yu, W. (2006). Evaluating the thermal stability of high performance fibers byTGA. Journal of Applied Polymer Science, 99, 937-944.

[17] Tao, Z., Jin J., Yang, S., Hu, D., Li, G. and Jiang, G. J. (2009). Synthesis and characterization offluorinated PBO with high thermal stability and low dielectric constant. Journal of Macromolecular Science, Part B, 48, 1114-1124.

[18] Abramoff, M. D., Magalhaes, P. J. and Ram, S. J. (2004). Image processing with Image J. Biophotonic International, 11 (7), 36-42. 